\title{
Measurements of atmospheric ${ }^{7}$ Be properties using high-efficiency gamma spectroscopy
}

\author{
K.N. Yu*, L.Y.L. Lee \\ Department of Physics and Materials Science, City University of Hong Kong, Tat Chee Avenue, Kowloon Tong, Kowloon, Hong Kong
}

Received 18 April 2002; received in revised form 6 June 2002; accepted 25 July 2002

\begin{abstract}
Two ${ }^{7}$ Be-related properties have been measured using a high-efficiency germanium gamma spectrometer (relative efficiency of $90 \%$ ), namely, the activity median aerodynamic diameter (AMAD) of ${ }^{7} \mathrm{Be}$-associated atmospheric aerosols and the airborne ${ }^{7} \mathrm{Be}$ radioactivity. With time resolutions of about $1-3 \mathrm{~d}$ correlations between these ${ }^{7} \mathrm{Be}-$ related properties and different meteorological parameters were identified. We found that AMAD is anti-correlated to ${ }^{7} \mathrm{Be}$ counts. It is correlated with the relative humidity $(\mathrm{RH})$ and mean cloud cover with high confidence, but not with temperature. We also found that ${ }^{7} \mathrm{Be}$ radioactivity was correlated with the $\mathrm{RH}$ with a moderate confidence, but not with the mean cloud cover or temperature. Furthermore, wet precipitation present in the middle of the sampling period decreased the ${ }^{7} \mathrm{Be}$ activity and increased the AMAD, while wet precipitation before or at the beginning of the sampling period decreased both ${ }^{7} \mathrm{Be}$ activity and AMAD. Finally, after a cold front passed by, the AMAD decreased and the ${ }^{7} \mathrm{Be}$ activity increased. Possible explanations are also given.
\end{abstract}

(C) 2002 Elsevier Science Ltd. All rights reserved.

Keywords: ${ }^{7} \mathrm{Be}$; Cosmogenic radionuclide; Meteorology; Gamma spectroscopy

\section{Introduction}

Natural ${ }^{7} \mathrm{Be}$ is formed by cosmic-ray spallation of nitrogen and oxygen in the atmosphere and can reach the ground level through vertical mixing in the troposphere. It has a half-life of $53.3 \mathrm{~d}$ or equivalently an average lifetime of $77 \mathrm{~d}$, and has been employed to study aerosol transit and residence times in the troposphere (Martell, 1970; Papastefanou and Ioannidou, 1995). Atmospheric aerosol particles in general follow a trimodal distribution including (a) the Aitken nuclei mode (from 0.003 to $0.07 \mu \mathrm{m}$, average $0.015 \mu \mathrm{m}$ ), (b) the accumulation mode (from 0.07 to $2 \mu \mathrm{m}$, average $0.3 \mu \mathrm{m}$ ), and (c) the coarse mode (from 2 to $36 \mu \mathrm{m}$, average $>10 \mu \mathrm{m})(\mathrm{NRC}, 1979)$. However, ${ }^{7} \mathrm{Be}$ associates mainly with the accumulation mode aerosols (Papastefanou and Ioannidou, 1995). After attachment, the transportation

\footnotetext{
*Corresponding author.

E-mail address: peter.yu@ cityu.edu.hk (K.N. Yu).
}

and deposition characteristics of ${ }^{7} \mathrm{Be}$ become those of the aerosol particles, so ${ }^{7} \mathrm{Be}$ is a good tracer for the characteristics of the accumulation mode aerosols.

Two ${ }^{7} \mathrm{Be}$ properties are studied in the present work. The first property is the activity median aerodynamic diameter (AMAD) derived from the aerodynamic size distribution of ${ }^{7} \mathrm{Be}$-associated atmospheric aerosols. From the AMAD, the residence time of the aerosols can also be determined. The second property is the airborne ${ }^{7} \mathrm{Be}$ radioactivity. It is noted that, in the literature, there are many more studies on ${ }^{7} \mathrm{Be}$ concentrations (e.g., Papastefanou et al., 1995; Talpos and Cuculeanu, 1997; Todorovic et al., 1999; Al-Azmi et al., 2001; Aldahan et al., 2001; El-Hussein et al., 2001) than on ${ }^{7} \mathrm{Be}$ size distribution (Papastefanou and Ioannidou, 1995; Winkler et al., 1998).

The first objective of the present work is to develop a fast method of measuring the above two ${ }^{7} \mathrm{Be}$ properties, aiming at a time resolution of $1 \mathrm{~d}$ by using a highefficiency germanium gamma spectrometer (relative 
efficiency of $90 \%$ ). Time resolutions for previous studies on ${ }^{7} \mathrm{Be}$ size distribution were of the order of $7 \mathrm{~d}$ (Papastefanou and Ioannidou, 1995) to $10 \mathrm{~d}$ (Winkler et al., 1998). The second objective is to study the correlation between these two ${ }^{7} \mathrm{Be}$ properties. With such time resolutions, the third objective is to identify correlations between ${ }^{7} \mathrm{Be}$ properties and different meteorological parameters. The meteorological parameters studied in the present work included the relative humidity (RH), mean cloud cover and temperature. Changes in the ${ }^{7} \mathrm{Be}$ properties with wet precipitation and the traversal of a cold front over Hong Kong are also investigated.

\section{Methodology}

\subsection{Air sampling}

Hong Kong $\left(22^{\circ} 18^{\prime} \mathrm{N}, 114^{\circ} 10^{\prime} \mathrm{E}\right)$ is a coastal city. The samples were collected $20 \mathrm{~m}$ above the ground on the roof of the Academic Building of the City University of Hong Kong. The samplings took place from late November to early March. This period mainly covers the winter and early spring seasons in Hong Kong, in which occasional rains and cold fronts can be encountered and wider ranges of $\mathrm{RH}$ and temperature can be expected.

The aerodynamic size distribution of ${ }^{7} \mathrm{Be}$-associated with atmospheric aerosols was obtained using Sierra's Series 230 cascade impactors (Anderson 2000, Inc., Atlanta, GA, USA), which involved a flow rate of $68 \mathrm{~m}^{3} \mathrm{~h}^{-1}$ (or $40 \mathrm{ft}^{3} \mathrm{~min}^{-1}$ ) and five atmospheric pressure stages for collecting aerosols larger than $0.49 \mu \mathrm{m}$. The effective cutoff diameters of these impactors were $0.49,0.95,1.5,3$ and $7.2 \mu \mathrm{m}$. Specially slotted glass-fibre filters were used to collect the aerosols on these stages. Another glass-fibre filter (without slots) used as a back up filter was used to collect all aerosol particles with diameters below $0.49 \mu \mathrm{m}$. Deposition of the particles in the glass-fiber lattice improves particle retention and reduces possible reentrainment.

We use sampling durations of exactly or very close to integral numbers of days in order to eliminate possible artifacts due to different sampling times. However, we also explored the sampling duration of $23 \mathrm{~h}$, which paves the way for continuous daily sampling in the future, if necessary. The remaining $1 \mathrm{~h}$ is required for collection and reload of the filter papers.

After collection, the glass fibre filters (with or without slots) were folded and wrapped around the inner vertical surface of a 41 Marinelli beaker, so that all filter papers will have the same irradiation geometry to the germanium detector.

\subsection{Gamma-ray spectrometer and calibration}

The ${ }^{7} \mathrm{Be}$ activities were measured using the gamma peak at $477 \mathrm{keV}$. The detector used was the EG\&G ORTEC GMX90240 photon detector spectrometer system (EG\&G ORTEC, 100 Midland Rd, Oak Ridge, TN 37831-0895). The type of cryostat configuration was Pop Top. The detector was an n-type coaxial high purity germanium crystal of $75.4 \mathrm{~mm} \times 91.1 \mathrm{~mm}$ with a relative efficiency of $90 \%$; this has a resolution of $2.18 \mathrm{keV}$ at $1.33 \mathrm{MeV}$. The detector is placed inside a lead shield of $52 \mathrm{~cm} \times 63.8 \mathrm{~cm}$ and $12 \mathrm{~cm}$ thickness. The ORTEC gamma vision for Windows A66-B32 version 5.1 software was used to control the data acquisition and storage as well as the sample analysis and calibration.

\subsection{AMAD and residence time of ${ }^{7}$ Be-associated aerosols}

The aerosol-attached ${ }^{7} \mathrm{Be}$ activity is approximated by a log-normal distribution. The AMAD and the geometric standard deviation (GSD) were conveniently determined by plotting the cumulative distributions on a piece of log-normal probability paper. In such a cumulative plot, the $x$-axis gives the logarithm of the aerodynamic diameter $\left(D_{p}\right)$ while the $y$-axis (in probit scale) indicates the cumulated percentage of ${ }^{7} \mathrm{Be}$ activity (out of the total sum of ${ }^{7} \mathrm{Be}$ activities on all stages) less than $D_{p}$.

If we plot the inverse of a cumulative Gaussian distribution (expressed as probabilities in percentages)

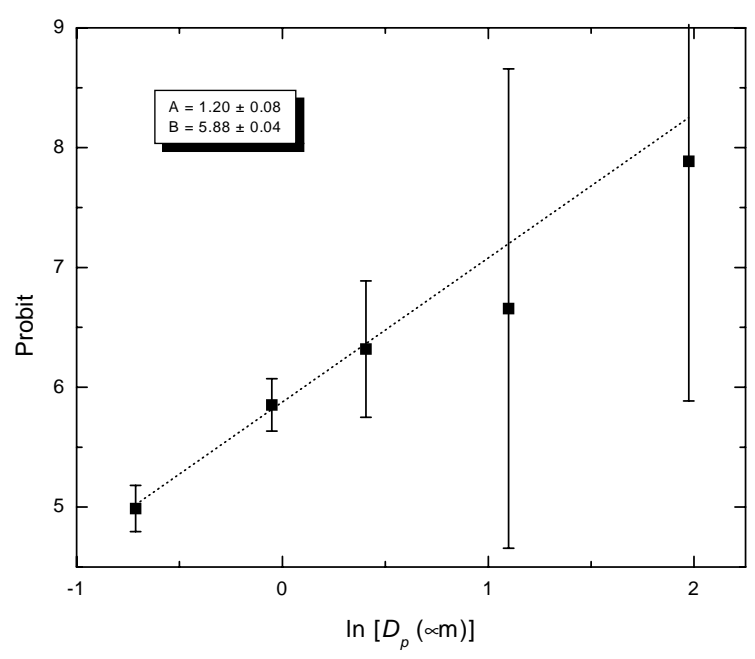

Fig. 1. An example of a plot of the cumulated percentage of ${ }^{7}$ Be activity versus the aerodynamic diameter $\left(D_{p}\right)$, in probit and $\ln$ scales, respectively. This plot employs the data collected for the period 20-22 January 2002. The best fit line $y=A x+B$ is shown by the dotted line. From the best-fit line, the AMAD is $0.48 \mu \mathrm{m}$ while the GSD is 2.3 . 
using a linear $y$ scale, we will get a sigmoidally shaped curve. Changing the $y$ scale to a (nonlinear) probability scale (ranging from 0.0001 to 99.999 ) can change the curve to appear as a straight line. The probit scale is similar to the probability scale, except that the scale is linear and the increment between tick marks is one standard deviation. The value " 5 " on the probit scale refers to the mean or $50 \%$ cumulative probability, while " 6 " refers to one standard deviation above the mean or $84.1 \%$ cumulative probability. A typical plot of the cumulated percentage of ${ }^{7} \mathrm{Be}$ activity versus the aerodynamic diameter $\left(D_{p}\right)$, in probit and $\log$ scales, respectively, is shown in Fig. 1. Hence, the AMAD is obtained by the $D_{p}$ value corresponding to the probit value of 5 , and the GSD by the ratio of $D_{p}$ values corresponding to probit values of 6 and 5 .

After obtaining the AMAD for a particular sample, the residence time $\tau_{R}$ can be estimated (Papastefanou and Ioannidou, 1995) by dividing the increase of the AMAD over the average size of the Aitken nuclei mode (i.e., $0.015 \mu \mathrm{m}$ ) by the mean growth rate of $0.004-0.005 \mu \mathrm{m} \mathrm{h}^{-1}$ (McMurray and Wilson, 1982).

\section{Results and discussion}

The results have been shown in Table 1. In the table, the sampling period, sampling duration, AMAD, GSD, corrected ${ }^{7} \mathrm{Be}$ counts, average temperature, $\mathrm{RH}$ and mean cloud cover are shown.

There were a total of 14 samplings: the first four sampled for $23 \mathrm{~h}$, the fifth for $72 \mathrm{~h}$, and the rest nine for $48 \mathrm{~h}$. The 2 nd -4 th data were obtained from continuous daily samplings, and the collection and reload of the filter papers were carried out during the $1 \mathrm{~h}$ period from 9 to 10 a.m. each day. The success of using a $23 \mathrm{~h}$ sampling period has made possible future continuous daily sampling.

The mean residence times for our samples were calculated to be $3.2-11.8 \mathrm{~d}$ (using a mean growth rate of $0.004 \mu \mathrm{m} \mathrm{h}^{-1}$ ) or 2.6-9.4 (using a mean growth rate of $0.005 \mu \mathrm{m} \mathrm{h}^{-1}$ ). Using the same method based on ${ }^{7} \mathrm{Be}$ measurements, Papastefanou and Ioannidou (1995) calculated the mean residence time of 7.4-8.9d. On the other hand, Papastefanou and Bondietti (1991) reported a mean residence time of $8 \mathrm{~d}$ for atmospheric aerosols in the boundary layer, as inferred from ${ }^{210} \mathrm{Bi} /{ }^{210} \mathrm{~Pb}$ activity ratios.

\subsection{Correlation between $A M A D$ and ${ }^{7}$ Be activity}

The relationship between AMAD and the corrected total ${ }^{7} \mathrm{Be}$ counts is shown in Fig. 2. All the ${ }^{7} \mathrm{Be}$ counts have been corrected to a sampling time of $48 \mathrm{~h}$. A negative relationship can be clearly observed between the two variables. Regression analysis shows the correlation coefficient between AMAD and the corrected total count to be -0.61 , and the significance of the regression is given by $p<0.03$ ( $F$ test). Therefore, AMAD is anti-correlated to ${ }^{7} \mathrm{Be}$ counts with high confidence.

As ${ }^{7} \mathrm{Be}$ is formed mainly in the stratosphere and also partly in the upper troposphere, we can expect that air coming from the upper troposphere or the stratosphere has enhanced ${ }^{7} \mathrm{Be}$ levels, and the corresponding time allowed for the AMAD to grow is relatively short. Feely

Table 1

Information regarding the sampling periods, average temperature, RH and mean cloud cover for our samples, and the derived values of AMAD and GSD

\begin{tabular}{|c|c|c|c|c|c|c|c|}
\hline Sampling period & $\begin{array}{l}\text { Sampling } \\
\text { duration (h) }\end{array}$ & $\begin{array}{l}\text { AMAD } \\
(\mu \mathrm{m})\end{array}$ & GSD & $\begin{array}{l}\text { Corrected } \\
\text { counts }\end{array}$ & $\mathrm{RH}(\%)$ & $\begin{array}{l}\text { Mean cloud } \\
\text { cover }(\%)\end{array}$ & $\begin{array}{l}\text { Average } \\
\text { temp }\left({ }^{\circ} \mathrm{C}\right)\end{array}$ \\
\hline 26/11/01(10:00)-27/11/01 (09:00) & 23 & 0.76 & 5.6 & 250 & 64.2 & 19.1 & 20.8 \\
\hline 29/11/01(10:00)-30/11/01 (09:00) & 23 & 0.67 & 2.1 & 445 & 87.1 & 73.0 & 22.4 \\
\hline $30 / 11 / 01(10: 00)-1 / 12 / 01(09: 00)$ & 23 & 0.68 & 2.5 & 392 & 77.9 & 61.5 & 21.6 \\
\hline $1 / 12 / 01(10: 00)-2 / 12 / 01(09: 00)$ & 23 & 0.79 & 3.4 & 230 & 81.5 & 75.5 & 22.5 \\
\hline $11 / 1 / 02(09: 41)-14 / 1 / 02(09: 41)$ & 72 & 0.74 & 1.8 & 607 & 80.1 & 70.9 & 20.7 \\
\hline $15 / 1 / 02(09: 35)-17 / 1 / 02(09: 35)$ & 48 & 0.51 & 2.6 & 431 & 89.6 & 66.8 & 20.6 \\
\hline $20 / 1 / 02(11: 30)-22 / 1 / 02(11: 30)$ & 48 & 0.48 & 2.3 & 531 & 62.0 & 37.0 & 13.4 \\
\hline 1/2/02 (16:00)-3/2/02 (16:00) & 48 & 0.60 & 2.1 & 454 & 74.1 & 87.7 & 14.0 \\
\hline 4/2/02 (10:00)-6/2/02 (10:00) & 48 & 1.15 & 1.9 & 356 & 80.6 & 91.9 & 16.2 \\
\hline $18 / 2 / 02(10: 00)-20 / 2 / 02(10: 00)$ & 48 & 0.55 & 2.0 & 616 & 71.9 & 47.9 & 18.7 \\
\hline $23 / 2 / 02(10: 00)-25 / 2 / 02(10: 00)$ & 48 & 0.71 & 2.0 & 543 & 82.2 & 67.6 & 19.9 \\
\hline $27 / 2 / 02(10: 00)-1 / 3 / 02(10: 00)$ & 48 & 0.75 & 2.3 & 596 & 83.8 & 67.3 & 21.7 \\
\hline $4 / 3 / 02(10: 00)-6 / 3 / 02(10: 00)$ & 48 & 0.60 & 3.0 & 514 & 71.1 & 69.6 & 20.0 \\
\hline $6 / 3 / 02(11: 00)-8 / 3 / 02(11: 00)$ & 48 & 0.33 & 2.5 & 868 & 50.9 & 41.4 & 18.5 \\
\hline
\end{tabular}




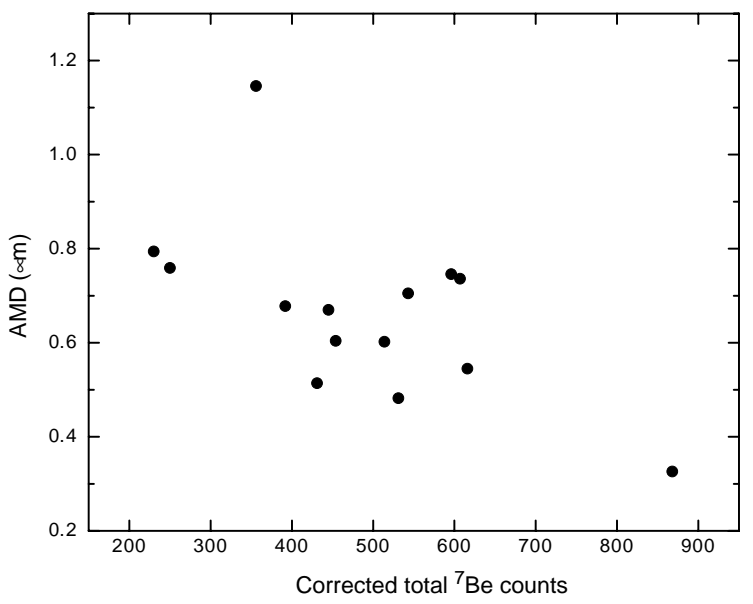

Fig. 2. Relationship between AMAD and the corrected total ${ }^{7}$ Be counts.

et al. (1989) also pointed out that downward transfer of ${ }^{7} \mathrm{Be}$ in the troposphere is a factor controlling variations of ${ }^{7} \mathrm{Be}$ radioactivities in the surface air. Therefore, for stronger vertical mixing in the troposphere, higher ${ }^{7} \mathrm{Be}$ levels and smaller AMAD values measured at the ground level are expected. Winkler et al. (1998) also observed relatively low AMAD values during the period of high ${ }^{7} \mathrm{Be}$ air concentrations.

\subsection{Correlation between ${ }^{7}$ Be properties and $R H$ and cloud cover}

Regression analysis shows the correlation coefficient between AMAD and the RH to be 0.50 , and the significance of the regression is given by $p<0.08$ ( $F$ test). Therefore, AMAD is correlated with the RH with high confidence. Shifts to large particle sizes were also observed for increased RH (Röbig et al., 1980). On the other hand, regression analysis shows the correlation coefficient between ${ }^{7} \mathrm{Be}$ counts and the RH to be -0.43 , and the significance of the regression is given by $p<0.13$ $\left(F\right.$ test). Therefore, ${ }^{7} \mathrm{Be}$ count is correlated with the $\mathrm{RH}$ with a moderate confidence. During high RH conditions, condensation becomes more intense, resulting in increased wet scavenging rate of aerosols and thus of ${ }^{7} \mathrm{Be}$ atoms attached to these sources (Gerasopoulos et al., 2001).

A similar relationship between AMAD and mean cloud cover has been found. The correlation coefficient is 0.49 and the significance of the regression is given by $p<0.08$ ( $F$ test). This can be similarly explained by shifts to large particle sizes when the aerosols pass through the clouds. However, the correlation coefficient between ${ }^{7} \mathrm{Be}$ counts and the mean cloud cover is only -0.17 , and the significance of the regression is given by $p<0.56$ ( $F$ test). Therefore, ${ }^{7} \mathrm{Be}$ count is not correlated with the mean cloud cover, and therefore the in-cloud wet scavenging does not eliminate the ${ }^{7} \mathrm{Be}$ attached aerosols.

\subsection{Correlation between ${ }^{7}$ Be properties and temperature}

The final studied meteorological parameter is the temperature. The correlation coefficients between AMAD and ${ }^{7} \mathrm{Be}$ counts with the temperature are 0.13 and -0.19 , respectively, while the corresponding significance are given by $p$ less than 0.66 and 0.52 , respectively. Therefore, it can be concluded that temperature does not affect the AMAD or the ${ }^{7} \mathrm{Be}$ counts, at least in our temperature range of $13-23^{\circ} \mathrm{C}$.

\subsection{Correlation between ${ }^{7}$ Be properties and wet precipitation}

In our data, two sampling periods had wet precipitation, namely, $1 / 2 / 02-3 / 2 / 02$, and 4/2/02-6/2/02. Rain fell in the middle of these two sampling periods, namely, $2.6 \mathrm{~mm}$ on 2 February 2002 and $1.9 \mathrm{~mm}$ on 5 February 2002. There was another sampling period, $15 / 1 / 02-17 / 1 /$ 02 , which had wet precipitation immediately before and at the beginning of the period, namely $1.7 \mathrm{~mm}$ on 14 January 2002 and $1 \mathrm{~mm}$ on 15 January 2002 .

The ${ }^{7} \mathrm{Be}$ properties seem to be very different for these two different scenarios. If the wet precipitation occurs in the middle of the sampling period, the total ${ }^{7} \mathrm{Be}$ activity decreases while the AMAD increases. For example, the total ${ }^{7} \mathrm{Be}$ activity decreases from 454 to 356 counts while the AMAD increases from 0.60 to $1.15 \mu \mathrm{m}$ from the period $1 / 2 / 02-3 / 2 / 02$ to the period $4 / 2 / 02-6 / 2 /$ 02 . The decrease in the ${ }^{7} \mathrm{Be}$ activity can be due to wet scavenging, while the increase in the AMAD is due to a shift to large particle size during rainfall (Röbig et al., 1980).

On the other hand, however, for the wet precipitation which occurs before or at the beginning of the sampling period, most particles, which had grown in size during rainfall, will not be sampled due to wet scavenging. Therefore, both ${ }^{7} \mathrm{Be}$ activity and the AMAD will decrease. This is the case for the period 15/1/02-17/1/ 02 , for which the ${ }^{7} \mathrm{Be}$ activity has decreased from 607 to 432 counts and the AMAD from 0.74 to $0.51 \mu \mathrm{m}$, when compared to the values for the previous sampling period.

However, these changes in AMAD and ${ }^{7} \mathrm{Be}$ activity can also be explained by the different $\mathrm{RH}$ values. In order to discuss clearly the effects of wet precipitation in the future, more data for various meteorological conditions are needed.

\subsection{Correlation between ${ }^{7}$ Be properties and cold fronts}

The data for the periods $20 / 1 / 02-22 / 1 / 02$ and $6 / 3 / 02-$ $8 / 3 / 02$ were obtained immediately after a cold front had 
passed Hong Kong. It can be seen that the AMAD values are relatively smaller than the values when the cold front was approaching or had just arrived. At the same time, the total ${ }^{7} \mathrm{Be}$ counts were also relatively higher after a cold front had passed by. These can be explained by the enhanced tropospheric mixing forced by the cold front systems, which is more efficient than the spontaneous convective mixing. Under such forced mixing, aerosol particles associated with freshly formed ${ }^{7} \mathrm{Be}$ can reach the ground level more easily so the airborne ${ }^{7} \mathrm{Be}$ activity will increase. The AMAD will also be smaller due to shorter residence time. Gerasopoulos et al. (2001) also observed that anticyclonic conditions favoured downward mixing of ${ }^{7} \mathrm{Be}$. Sometimes the tropopause actually folds down just behind a cold front, and the subsided stratospheric air will bring along an enhanced ${ }^{7} \mathrm{Be}$ activity.

However, again, these changes in AMAD and ${ }^{7} \mathrm{Be}$ activity can also be explained by the different $\mathrm{RH}$ values. In order to discuss clearly the effects of a cold front in the future, more data for various meteorological conditions are needed.

\section{Conclusions}

(1) Two ${ }^{7}$ Be-related properties have been measured using a high-efficiency germanium gamma spectrometer (relative efficiency of 90\%), namely, the AMAD of ${ }^{7} \mathrm{Be}$-associated atmospheric aerosols, and the airborne ${ }^{7} \mathrm{Be}$ radioactivity.

(2) We have been successful in using a $23 \mathrm{~h}$ sampling period to measure the above two ${ }^{7} \mathrm{Be}$-related properties, which has made possible future continuous daily sampling. Time resolutions for previous studies of residence time using ${ }^{7} \mathrm{Be}$ were of the order of $7-10 \mathrm{~d}$.

(3) The mean residence times for our samples were calculated to be $3.2-11.8 \mathrm{~d}$ (using a mean growth rate of $0.004 \mu \mathrm{m} \mathrm{h}^{-1}$ ) or 2.6-9.4 (using a mean growth rate of $0.005 \mu \mathrm{m} \mathrm{h}^{-1}$ ).

(4) AMAD is anti-correlated to ${ }^{7} \mathrm{Be}$ counts with high confidence.

(5) AMAD is correlated with the RH with high confidence, while ${ }^{7} \mathrm{Be}$ radioactivity is correlated with the RH with a moderate confidence.

(6) AMAD is correlated with the mean cloud cover with high confidence, while ${ }^{7} \mathrm{Be}$ radioactivity is not correlated with the mean cloud cover.

(7) Temperature does not affect the AMAD or the ${ }^{7} \mathrm{Be}$ counts, at least in our temperature range of 13$23^{\circ} \mathrm{C}$.

(8) Wet precipitation in the middle of the sampling period decreases the ${ }^{7} \mathrm{Be}$ activity and increases the AMAD, while wet precipitation before or at the beginning of the sampling period decreases both
${ }^{7}$ Be activity and AMAD. After a cold front has passed by, the AMAD decreases and the ${ }^{7} \mathrm{Be}$ activity increases. However, these changes in AMAD and ${ }^{7}$ Be activity can also be explained by the different RH values. In order to discuss clearly the effects of rainfall and cold fronts in the future, more data for various meteorological conditions are needed.

\section{References}

Al-Azmi, D., Sayed, A.M., Yatim, H.A., 2001. Variations in ${ }^{7} \mathrm{Be}$ concentrations in the atmosphere of Kuwait during the period of 1994-1998. Appl. Radiat. Isot. 55, 413-417.

Aldahan, A., Possnert, G., Vintersved, I., 2001. Atmospheric interactions at northern high latitudes from weekly Be-isotopes in surface air. Appl. Radiat. Isot. 54, 345-353.

El-Hussein, A., Mohamemed, A., El-Hady, M.A., Ahmed, A.A., Ali, A.E., Barakat, A., 2001. Diurnal and seasonal variation of short-lived radon progeny concentration and atmospheric temporal variations of ${ }^{210} \mathrm{~Pb}$ and ${ }^{7} \mathrm{Be}$ in Egypt. Atmos. Environ. 35, 4305-4313.

Feely, H.W., Larsen, R.J., Sanderson, C.G., 1989. Factors that cause seasonal variations in ${ }^{7} \mathrm{Be}$ concentrations in surface air. J. Environ. Radioact. 9, 223-249.

Gerasopoulos, E., Zanis, P., Stohl, A., Zerefos, C.S., Papastefanou, C., Ringer, W., Tobler, L., Hübener, S., Gäggeler, H.W., Kanter, H.J., Tositti, L., Sandrini, S., 2001. A climatology of ${ }^{7} \mathrm{Be}$ at four high-altitude stations at the alps and the northern Appennines. Atmos. Environ. 35, 6347-6360.

Martell, E.A., 1970. Transport patterns and residence times for atmospheric trace constituents vs. altitude. In: Radionuclides in the Environment. Advances in Chemistry Series, Vol. 93, American Chemical Society, Washington, DC, pp. $138-157$.

McMurray, P.H., Wilson, J.C., 1982. Growth laws for the formation of secondary ambient aerosols: implications for chemical conversion mechanisms. Atmos. Environ. 16, 121-134.

NRC, National Research Council, 1979. Airborne Particles. University Park Press, Baltimore, USA.

Papastefanou, C., Bondietti, E.A., 1991. Mean residence times of atmospheric aerosols in the boundary layer as determined from ${ }^{210} \mathrm{Bi} /{ }^{210} \mathrm{~Pb}$ activity ratios. J. Aerosol Sci. 22, 927-931.

Papastefanou, C., Ioannidou, A., 1995. Aerodynamic size association of ${ }^{7} \mathrm{Be}$ in ambient aerosols. J. Environ. Radioact. 26, 273-282.

Papastefanou, C., Ioannidou, A., Stoulos, S., Manolopoulou, M., 1995. Atmospheric deposition of cosmogenic ${ }^{7} \mathrm{Be}$ abd ${ }^{137}$ Cs from fallout of the Chernobyl accident. Sci. Total Environ. 170, 151-156.

Röbig, G., Becker, K.H., Hessin, A., Porstendörfer, J., Scheibel, H.G., 1980. A cascade impactor calibration for measurement of activity size distributions in the 
atmosphere. In: Proceedings of the Eighth Conference in Aerosol Science, GeorgAugust University, Göttingen, Germany, pp. 96-102.

Talpos, S., Cuculeanu, V., 1997. A study of the vertical diffusion of ${ }^{7} \mathrm{Be}$ in the atmosphere. J. Environ. Radioact. 36, 93-106.
Todorovic, D., Popovic, D., Djuric, G., 1999. Concentration measurements of ${ }^{7} \mathrm{Be}$ and ${ }^{137} \mathrm{Cs}$ in ground level air in the belgrade city area. Environ. Int. 25, 59-66.

Winkler, R., Dietl, F., Frank, G., Tschiersch, J., 1998. Temporal variation of ${ }^{7} \mathrm{Be}$ and ${ }^{210} \mathrm{~Pb}$ size distributions in ambient aerosol. Atmos. Environ. 32, 983-991. 